\title{
Delivery of maternal health care in Indigenous primary care services: baseline data for an ongoing quality improvement initiative
}

\author{
Alice R Rumbold ${ }^{1,2^{*}}$, Ross S Bailie ${ }^{2}$, Damin $\mathrm{Si}^{3}$, Michelle C Dowden ${ }^{4}$, Catherine M Kennedy ${ }^{5}$, Rhonda J Cox ${ }^{6}$, \\ Lynette O'Donoghue ${ }^{2}$, Helen E Liddle ${ }^{7}$, Ru K Kwedza ${ }^{8}$, Sandra C Thompson ${ }^{6}$, Hugh P Burke ${ }^{5}$, Alex DH Brown ${ }^{9}$, \\ Tarun Weeramanthri ${ }^{10}$, Christine M Connors ${ }^{11}$
}

\begin{abstract}
Background: Australia's Aboriginal and Torres Strait Islander (Indigenous) populations have disproportionately high rates of adverse perinatal outcomes relative to other Australians. Poorer access to good quality maternal health care is a key driver of this disparity. The aim of this study was to describe patterns of delivery of maternity care and service gaps in primary care services in Australian Indigenous communities.
\end{abstract}

Methods: We undertook a cross-sectional baseline audit for a quality improvement intervention. Medical records of 535 women from 34 Indigenous community health centres in five regions (Top End of Northern Territory 13, Central Australia 2, Far West New South Wales 6, Western Australia 9, and North Queensland 4) were audited. The main outcome measures included: adherence to recommended protocols and procedures in the antenatal and postnatal periods including: clinical, laboratory and ultrasound investigations; screening for gestational diabetes and Group B Streptococcus; brief intervention/advice on health-related behaviours and risks; and follow up of identified health problems.

Results: The proportion of women presenting for their first antenatal visit in the first trimester ranged from 34\% to $49 \%$ between regions; consequently, documentation of care early in pregnancy was poor. Overall, documentation of routine antenatal investigations and brief interventions/advice regarding health behaviours varied, and generally indicated that these services were underutilised. For example, $46 \%$ of known smokers received smoking cessation advice/counselling; $52 \%$ of all women received antenatal education and $51 \%$ had investigation for gestational diabetes. Overall, there was relatively good documentation of follow up of identified problems related to hypertension or diabetes, with over 70\% of identified women being referred to a GP/Obstetrician.

Conclusion: Participating services had both strengths and weaknesses in the delivery of maternal health care. Increasing access to evidence-based screening and health information (most notably around smoking cessation) were consistently identified as opportunities for improvement across services.

\section{Background}

Approximately four percent of women giving birth in Australia are Aboriginal and/or Torres Strait Islander (Indigenous) [1]. Disproportionately high rates of poor pregnancy outcomes including maternal and perinatal mortality, preterm birth and low birth weight have

\footnotetext{
* Correspondence: alice.rumbold@adelaide.edu.au

'Discipline of Obstetrics and Gynaecology, The University of Adelaide, Adelaide, SA, Australia

Full list of author information is available at the end of the article
}

consistently been documented in Indigenous populations relative to other Australians [2]. With the exception of perinatal mortality, little improvement in these outcomes has occurred in the past two decades [1], and for some outcomes (e.g. low birth weight), the disparity appears to be widening [3].

Providing access to appropriate and quality care in the antenatal and postnatal period is a key part of closing the gap in Indigenous perinatal outcomes. It also offers an important opportunity to ameliorate disease in adult

\section{Ciomed Central}


life, given the recognised link between early life influences and chronic disease [4].

Antenatal care aims to provide appropriate screening, preventive or treatment interventions and health information to maximise the health of women and their infants [5]. Almost all pregnant Australian women have some antenatal care, which can be delivered by a diverse range of providers (e.g. midwives, obstetricians, Aboriginal health workers, general practitioners etc.) working across hospital and community settings. However, Indigenous women access care differently to other Australian women. Although there is no complete national data for Indigenous women, the available data suggests that antenatal care is underutilised, as Indigenous women are more likely to present for care later in pregnancy and have fewer antenatal visits [6-8].

The importance of achieving equity in access to antenatal care is recognised in several local and international development initiatives $[9,10]$. However, improving the quality of care is also important, as poor quality care can contribute to poor outcomes [11] and be a barrier to service utilisation [12]. Previous research assessing care for Aboriginal women birthing in the Northern Territory (NT) identified the need to focus on accurate assessment and follow up of problems identified in pregnancy, and other aspects of quality of care, rather than focusing solely on the timing and frequency of antenatal visits [13]. Furthermore, there is evidence of sustained improvements in perinatal outcomes amongst women attending a large Aboriginal Medical Service in Queensland that focussed on quality improvement in maternal and child health $[14,15]$.

Recognising the potential benefits of quality improvement principles in primary health care, the Australian Government launched the Healthy for Life program in 2005 [16]. The program aimed to improve the capacity of and care offered by Aboriginal primary health care services for chronic disease and maternal and child health, and drew extensively from a quality improvement action research project that has been operating since 2002 - the Audit and Best practice for Chronic Disease (ABCD) Project [17]. Here we describe patterns of delivery of maternal health services and gaps in these services drawing on data from this project.

\section{Methods}

The data presented here arise from baseline clinical audits undertaken in the ABCD Project. Of 56 participating primary health care centres in early 2009, 34 elected to audit their maternal health records. These centres were located in: a) remote communities in the Top End (13) and Central Australia (2) of the NT and in North Queensland (QLD) (4); and b) small regional towns in Far West New South Wales (NSW) (6) and
Western Australia (WA) (9). Participating services were widely distributed across Australia and many of the remote health centres were located in sparsely populated areas in the northern part of Australia.

Delivery of maternal health care was assessed by auditing a sample of clinical records from participating services. Records of women with an infant aged between 2-14 months and who were resident in the community for at least six months of that infant's gestation were eligible. From eligible records in each service, a random sample of up to 30 records was drawn using computer generated random numbers. Where there were fewer than 30 eligible records all were included for audit. In the ACBD project these sampling methods have been demonstrated to be sufficient to show meaningful differences between communities and trends over time.

The audit was based on previous research [18], published antenatal guidelines [19], the Women's Business Manual (WBM) [20] and key literature [21-24]. The WBM is the standard management manual for practitioners caring for women in remote areas.

The audits were conducted by trained members of the project team familiar with the auditing process and the maternal audit tool, in collaboration with local health staff. The audit form and protocol are available at: <http://www.abcdproject.org.au >. A clinical service related to antenatal/postnatal care was assessed as "delivered" if there was a record of the service being delivered at specific periods in line with antenatal/postnatal care guidelines.

We have previously published a short report on selected data from this study [25]. Here we present a more complete analysis of the data.

The study was approved by the human research ethics committees in the Top End of the NT, Central Australia, Far West NSW, WA and Cairns and Townsville, and their Indigenous sub-committees where required.

\section{Results}

The records of 535 women (NT Top End 136, Central Australia 45, Far West NSW 103, WA 193, and North QLD 58) from the 34 participating services were audited (Table 1). Most (59\%) services were managed by a local or regional Indigenous committee/board, 38\% were accredited practices and half served communities with 1000 members or more.

Across services the median age of women was 25.3 years (range 14-48) (Table 1). Compared with services in the NT, WA and North QLD, Far West NSW had a higher proportion of non-Indigenous women presenting for antenatal or postnatal care $(\mathrm{P}<0.05)$, however, overall $89 \%$ of all women were Indigenous.

Across services, the proportion of women presenting for their first antenatal visit in the first trimester ranged 
Table 1 Characteristics of participating health centres, women and early pregnancy care

\begin{tabular}{|c|c|c|c|c|c|c|}
\hline Characteristic & $\begin{array}{l}\text { NT Top } \\
\text { End }\end{array}$ & $\begin{array}{l}\text { NT Central } \\
\text { Australia }\end{array}$ & $\begin{array}{l}\text { Far West } \\
\text { NSW }\end{array}$ & WA & North QLD & Total \\
\hline No. of health centres & 13 & 2 & 6 & 9 & 4 & 34 \\
\hline \multicolumn{7}{|l|}{ Governance models of health centres } \\
\hline Government funded/operated & $7(54 \%)$ & $0(0 \%)$ & $0(0 \%)$ & $3(33 \%)$ & $4(100 \%)$ & $14(41 \%)$ \\
\hline $\begin{array}{l}\text { Managed by local or regional Indigenous committee } \\
\text { or board }\end{array}$ & $6(46 \%)$ & $2(100 \%)$ & $6(100 \%)$ & $6(67 \%)$ & $0(0 \%)$ & $20(59 \%)$ \\
\hline \multicolumn{7}{|l|}{ Accreditation status } \\
\hline Accredited & $6(46 \%)$ & $2(100 \%)$ & $0(0 \%)$ & $4(44 \%)$ & $1(25 \%)$ & $13(38 \%)$ \\
\hline Not accredited & 7 (54\%) & $0(0 \%)$ & $6(100 \%)$ & $5(56 \%)$ & $3(75 \%)$ & $21(62 \%)$ \\
\hline \multicolumn{7}{|l|}{ Population sizes of communities served } \\
\hline$\leq 500$ & $4(31 \%)$ & $0(0 \%)$ & $1(17 \%)$ & $0(0 \%)$ & $1(25 \%)$ & $6(18 \%)$ \\
\hline $501-999$ & $4(31 \%)$ & $1(50 \%)$ & $3(50 \%)$ & $1(11 \%)$ & $2(50 \%)$ & $11(32 \%)$ \\
\hline$\geq 1000$ & $5(38 \%)$ & $1(50 \%)$ & $2(33 \%)$ & $8(89 \%)$ & $1(25 \%)$ & $17(50 \%)$ \\
\hline No. of women participating in maternal health audits & 136 & 45 & 103 & 193 & 58 & 535 \\
\hline Median age of women (years) & 23.7 & 24.8 & 25.8 & 26.2 & 26.4 & 25.3 \\
\hline \multicolumn{7}{|l|}{ Indigenous status } \\
\hline Indigenous & $96 \%$ & $100 \%$ & $61 \%$ & $93 \%$ & $95 \%$ & $89 \% *$ \\
\hline Non-Indigenous & $3 \%$ & $0 \%$ & $34 \%$ & $6 \%$ & $0 \%$ & $9 \%^{*}$ \\
\hline Not stated & $1 \%$ & $0 \%$ & $5 \%$ & $1 \%$ & $5 \%$ & $2 \%$ \\
\hline $\begin{array}{l}\text { Mean estimated gestational age at the first antenatal visit } \\
\text { (weeks) }\end{array}$ & 14 & 15 & 20 & 15 & 15 & 16 \\
\hline $\begin{array}{l}\text { Proportion of women with estimated gestational age at } \\
\text { first antenatal visit }<12 \text { weeks }\end{array}$ & $49 \%$ & $44 \%$ & $35 \%$ & $42 \%$ & $34 \%$ & $42 \%$ \\
\hline Mean number of antenatal visits & 9 & 10 & 5 & 6 & 7 & $7^{*}$ \\
\hline \multicolumn{7}{|l|}{ First antenatal assessments by: } \\
\hline Aboriginal health workers & $9 \%$ & $0 \%$ & $2 \%$ & $5 \%$ & $5 \%$ & $5 \%$ \\
\hline Nurses & $25 \%$ & $2 \%$ & $3 \%$ & $17 \%$ & $33 \%$ & $17 \% *$ \\
\hline Midwives & $40 \%$ & $82 \%$ & $50 \%$ & $25 \%$ & $28 \%$ & $39 \% *$ \\
\hline Doctors & $10 \%$ & $16 \%$ & $13 \%$ & $51 \%$ & $3 \%$ & $25 \% *$ \\
\hline Unknown & $16 \%$ & $0 \%$ & $32 \%$ & $2 \%$ & $31 \%$ & $14 \% *$ \\
\hline $\begin{array}{l}\text { Proportion of women with folic acid prescribed before } 20 \\
\text { weeks }\end{array}$ & $29 \%$ & $49 \%$ & $3 \%$ & $33 \%$ & $24 \%$ & $27 \% *$ \\
\hline $\begin{array}{l}\text { Proportion of women with folic acid prescribed prior to } \\
\text { conception }\end{array}$ & $12 \%$ & $7 \%$ & $0 \%$ & $8 \%$ & $16 \%$ & $8 \%$ \\
\hline Proportion of women with iron prescribed & $76 \%$ & $73 \%$ & $29 \%$ & $63 \%$ & $41 \%$ & $58 \% *$ \\
\hline $\begin{array}{l}\text { Proportion of women with a general antenatal care plan } \\
\text { present in the file }\end{array}$ & $93 \%$ & $98 \%$ & $65 \%$ & $82 \%$ & $86 \%$ & $83 \%$ \\
\hline
\end{tabular}

${ }^{*} \mathrm{P}<0.05$ for comparisons between regions.

from $34 \%$ to $49 \%$ and the mean gestational age at first visit was 16 weeks (range 3-40). The first antenatal assessment was undertaken by a variety of providers; with the exception of WA and North QLD services, the most common provider was a midwife (Table 1).

Documentation of prescription of folic acid was poor. Across all services only $27 \%$ of women were prescribed folic acid prior to 20 weeks gestation and even fewer (8\%) prior to conception. In contrast, more than half of women in most services were prescribed iron during pregnancy. Over $80 \%$ of women had an antenatal care plan recorded in their file (Table 1).
The mean gestational age at birth was 38.6 weeks, and the majority of women had a vaginal birth (67\%) (Table 2). The proportion of women who gave birth to an infant weighing $<2500$ grams ranged from $5-15 \%$ across services.

Recorded use of cigarettes at any time in the pregnancy was high across all services (43\% in total), followed by use of alcohol (22\%) and illicit drugs (9\%) (Table 3). Among those who used cigarettes, $46 \%$ had documented advice regarding smoking cessation. Just over a third of all women had documented medical risk factors, and one-fifth had recorded social risk factors (e.g. related to domestic/social environment, finances or 
Table 2 Birth outcomes

\begin{tabular}{|c|c|c|c|c|c|c|}
\hline & NT Top End & NT Central Australia & Far West NSW & WA & North QLD & Total \\
\hline No. of health centres | client records & $13 \mid 136$ & $2 \mid 45$ & \begin{tabular}{l|l|l}
6 & 103
\end{tabular} & 9 | 193 & $4 \mid 58$ & $34 \mid 535$ \\
\hline Mean gestational age at birth (weeks) & 38.8 & 38.8 & 38.8 & 38.4 & 38.3 & 38.6 \\
\hline Mean infant birth weight $\left(\right.$ grams) ${ }^{\dagger}$ & 3203 & 3391 & 3415 & 3101 & 2995 & $3198^{*}$ \\
\hline Proportion of infants $<2500$ grams at birth ${ }^{\dagger}$ & $5 \%$ & $7 \%$ & $5 \%$ & $14 \%$ & $15 \%$ & $10 \%$ \\
\hline Proportion of infants $<37$ weeks gestation & $6 \%$ & $11 \%$ & $7 \%$ & $14 \%$ & $15 \%$ & $11 \%$ \\
\hline \multicolumn{7}{|l|}{ Type of birth } \\
\hline Vaginal & $64 \%$ & $69 \%$ & $60 \%$ & $77 \%$ & $52 \%$ & $67 \%$ \\
\hline Caesarean section & $25 \%$ & $29 \%$ & $23 \%$ & $22 \%$ & $8 \%$ & $22 \% *$ \\
\hline Unknown & $11 \%$ & $2 \%$ & $17 \%$ & $1 \%$ & $40 \%$ & $11 \% *$ \\
\hline
\end{tabular}

†Birth weights were known for 468 infants, which accounted for $87 \%$ of the whole sample.

${ }^{*} \mathrm{P}<0.05$ for comparisons between regions.

family/social support). The proportion of these risk factors was significantly different across regions. Documentation of brief interventions/advice regarding health behaviour/risks varied; $52 \%$ of women received antenatal education, whilst enquiries and advice around housing conditions, financial security and food security were the least frequently recorded (range, 6-11\% for all women).

Consistent with the late gestational age at first presentation observed across services, documentation of routine antenatal checks including maternal height/weight, blood pressure and urinalysis before 13 weeks gestation was poor (range $10-45 \%$ for all women), but improved for checks undertaken between 13-24 weeks gestation (range $61-71 \%$ for all women), and after 24 weeks gestation (range $72-81 \%$ for all women) (Table 3). There was significant variation between regions in the frequency of routine antenatal checks.

Recording of routine laboratory investigations was high for most investigations undertaken at the first antenatal visit (range $63-82 \%$ for all women) (Table 4 ), with the exception of fetal anomaly screening (either nuchal translucency, first trimester combined screen or maternal serum screening, $15 \%$ for all women).

Documentation of routine ultrasound varied between regions. Overall only $42 \%$ of women had a recorded ultrasound between 16-20 weeks gestation for fetal morphology (range 31-69\% across regions) (Table 4). Similarly documentation of screening or diagnostic tests for gestational diabetes mellitus (GDM) varied (51\% for all women, range $33-78 \%$ ) as did investigation for Group B Streptococcus (GBS) infection (35\% for all women, range 10-62\%).

Documentation of follow up of identified problems varied (Table 5). Amongst women with an abnormal BP reading either before or after 28 weeks gestation, over $70 \%$ were referred to and examined by a GP or obstetrician and had follow up BP measurements. Similarly, amongst women with an abnormal screening test for GDM, 77\% had a diagnostic oral glucose tolerance test. The proportion of women with a Rhesus negative blood group was low (3\%), and compliance with anti-D injections varied depending on the recommended timing of the injection in the antenatal (range 40-50\% for all women) and postnatal period (range 0-100\%). Less than a third of all women with inadequate immunity had rubella immunisation documented postnatally.

Although $53 \%$ of women had a recorded postnatal visit, documentation of advice regarding health risk factors was poor (Table 6). For around half of all women there was documentation about breastfeeding advice and contraception. However advice about smoking, nutrition and mood (depression) were infrequently recorded (range 19-21\% for all women), as was advice around sudden infant death syndrome (SIDS) prevention, injury prevention and infection/hygiene (range 4-5\% for all women).

\section{Discussion}

The clinical audit data presented here provide insights into documented delivery of maternity care which should be useful for informing local, regional and national efforts to promote the quality of primary maternal health care for Indigenous women. Participating services varied in their relative strengths and weaknesses, both geographically and between service items. Nevertheless, adherence to recommended screening investigations and brief interventions/advice about health behaviours were consistently identified as areas for improvement across services.

This study extends previous work demonstrating improvements in antenatal screening at a local level $[14,15]$ and indicates the potential for improvements to be replicated on a broad scale. The study also demonstrates the potential for quality improvement methods to be extended to systematic assessment of other aspects of care including follow up of abnormal clinical findings. In addition, this study adds to the limited international literature on approaches to assessing the quality of antenatal care in primary care settings. 
Table 3 Recording of pregnancy risk factors and brief interventions and delivery of routine antenatal checks

\begin{tabular}{|c|c|c|c|c|c|c|}
\hline Item & NT Top End & NT Central Australia & Far West NSW & WA & North QLD & Total \\
\hline No. of health centres | client records & $13 \mid 136$ & $2 \mid 45$ & $6 \mid 103$ & $9 \mid 193$ & $4 \mid 58$ & $34 \mid 535$ \\
\hline Any use of: Cigarettes & $41 \%$ & $40 \%$ & $39 \%$ & $42 \%$ & $55 \%$ & $43 \%^{+}$ \\
\hline Alcohol & $12 \%$ & $27 \%$ & $19 \%$ & $25 \%$ & $31 \%$ & $22 \% *$ \\
\hline Illicit drugs & $7 \%$ & $2 \%$ & $17 \%$ & $8 \%$ & $7 \%$ & $9 \%$ \\
\hline $1^{\text {st }}$ trimester: Cigarettes & $32 \%$ & $27 \%$ & $24 \%$ & $32 \%$ & $43 \%$ & $31 \%$ \\
\hline Alcohol & $9 \%$ & $24 \%$ & $13 \%$ & $18 \%$ & $28 \%$ & $16 \%$ \\
\hline Illicit drugs & $5 \%$ & $2 \%$ & $9 \%$ & $6 \%$ & $3 \%$ & $6 \%$ \\
\hline $3^{\text {rd }}$ trimester: Cigarettes & $21 \%$ & $38 \%$ & $35 \%$ & $26 \%$ & $50 \%$ & $30 \%$ \\
\hline Alcohol & $4 \%$ & $13 \%$ & $17 \%$ & $14 \%$ & $21 \%$ & $13 \%$ \\
\hline Illicit drugs & $3 \%$ & $0 \%$ & $15 \%$ & $6 \%$ & $7 \%$ & $6 \%$ \\
\hline Evidence of: Social risk factors & $11 \%$ & $29 \%$ & $6 \%$ & $22 \%$ & $57 \%$ & $20 \% *$ \\
\hline Medical risk factors & $38 \%$ & $64 \%$ & $19 \%$ & $39 \%$ & $45 \%$ & $38 \% *$ \\
\hline \multicolumn{7}{|l|}{ Brief interventions/counselling } \\
\hline Smoking cessation ${ }^{\ddagger}$ & $48 \%$ & $67 \%$ & $35 \%$ & $49 \%$ & $41 \%$ & $46 \%$ \\
\hline Antenatal education & $51 \%$ & $93 \%$ & $51 \%$ & $46 \%$ & $47 \%$ & $52 \% *$ \\
\hline Nutrition & $53 \%$ & $76 \%$ & $18 \%$ & $32 \%$ & $59 \%$ & $41 \% *$ \\
\hline Oral health & $33 \%$ & $29 \%$ & $5 \%$ & $9 \%$ & $7 \%$ & $16 \% *$ \\
\hline Breast feeding & $21 \%$ & $51 \%$ & $17 \%$ & $25 \%$ & $19 \%$ & $24 \%$ \\
\hline Alcohol and other substance abuse & $37 \%$ & $56 \%$ & $12 \%$ & $39 \%$ & $34 \%$ & $34 \% *$ \\
\hline Physical activity & $27 \%$ & $36 \%$ & $5 \%$ & $17 \%$ & $38 \%$ & $21 \% *$ \\
\hline Mood (depression) & $14 \%$ & $51 \%$ & $11 \%$ & $20 \%$ & $19 \%$ & $19 \% *$ \\
\hline Domestic/social environment & $24 \%$ & $58 \%$ & $10 \%$ & $16 \%$ & $29 \%$ & $22 \%$ \\
\hline Social/family support & $38 \%$ & $73 \%$ & $5 \%$ & $29 \%$ & $24 \%$ & $30 \% *$ \\
\hline Financial situation & $2 \%$ & $29 \%$ & $1 \%$ & $6 \%$ & $7 \%$ & $6 \% *$ \\
\hline Housing condition & $4 \%$ & $44 \%$ & $1 \%$ & $15 \%$ & $9 \%$ & $11 \% *$ \\
\hline Food security & $2 \%$ & $33 \%$ & $1 \%$ & $8 \%$ & $7 \%$ & $7 \% *$ \\
\hline \multicolumn{7}{|l|}{ Routine antenatal checks } \\
\hline \multicolumn{7}{|l|}{ Before 13 weeks gestation } \\
\hline Weight & $55 \%$ & $56 \%$ & $26 \%$ & $33 \%$ & $38 \%$ & $40 \%$ \\
\hline Maternal height & $18 \%$ & $29 \%$ & $15 \%$ & $19 \%$ & $26 \%$ & $20 \%$ \\
\hline BMI & $6 \%$ & $27 \%$ & $2 \%$ & $14 \%$ & $7 \%$ & $10 \% *$ \\
\hline $\mathrm{BP}$ & $57 \%$ & $56 \%$ & $33 \%$ & $38 \%$ & $50 \%$ & $45 \%$ \\
\hline Urinalysis & $57 \%$ & $53 \%$ & $24 \%$ & $34 \%$ & $34 \%$ & $40 \% *$ \\
\hline \multicolumn{7}{|l|}{ Between 13 and 24 weeks gestation } \\
\hline Fundal height & $80 \%$ & $80 \%$ & $36 \%$ & $58 \%$ & $67 \%$ & $62 \% *$ \\
\hline FHR & $76 \%$ & $78 \%$ & $45 \%$ & $57 \%$ & $57 \%$ & $61 \% *$ \\
\hline $\mathrm{BP}$ & $80 \%$ & $82 \%$ & $54 \%$ & $67 \%$ & $83 \%$ & $71 \%$ \\
\hline Urinalysis & $79 \%$ & $76 \%$ & $29 \%$ & $61 \%$ & $59 \%$ & $61 \%^{*}$ \\
\hline \multicolumn{7}{|l|}{ After 24 weeks gestation } \\
\hline Fundal height & $93 \%$ & $89 \%$ & $66 \%$ & $69 \%$ & $64 \%$ & $76 \% *$ \\
\hline $\mathrm{FHR}$ & $93 \%$ & $89 \%$ & $70 \%$ & $69 \%$ & $60 \%$ & $76 \% *$ \\
\hline $\mathrm{BP}$ & $93 \%$ & $91 \%$ & $71 \%$ & $75 \%$ & $78 \%$ & $81 \% *$ \\
\hline Urinalysis & $95 \%$ & $89 \%$ & $52 \%$ & $68 \%$ & $57 \%$ & $72 \% *$ \\
\hline
\end{tabular}

$\mathrm{BMI}=$ body mass index, $\mathrm{FHR}=$ fetal heart rate, $\mathrm{BP}=$ blood pressure.

${ }^{*} \mathrm{P}<0.05$ for comparisons between regions.

†The reason that the proportion of women smoking at any time in pregnancy is higher than in either the first or third trimester is that of the $228(43 \%)$ who had smoked at any stage during pregnancy, 101 smoked in both $1^{\text {st }}$ and $3^{\text {rd }}$ trimesters, 66 smoked only in $1^{\text {st }}$ trimester, and 61 smoked only in $3^{\text {rd }}$ trimester. Thus a proportion of women appear to have taken up smoking between the $1^{\text {st }}$ and $3^{\text {rd }}$ trimesters and a proportion who smoked in the first trimester were reported to no longer smoke in the $3^{\text {rd }}$ trimester.

FAmong those who used cigarettes: NT Top End $(n=56)$; NT Central Aust $(n=18)$; Far West NSW $(n=40)$; WA $(n=82)$; North Qld $(n=32)$; total N $=228$. 
Table 4 Delivery of laboratory and ultrasound investigations

\begin{tabular}{|c|c|c|c|c|c|c|}
\hline Service item & $\begin{array}{l}\text { NT Top } \\
\text { End }\end{array}$ & $\begin{array}{l}\text { NT Central } \\
\text { Australia }\end{array}$ & $\begin{array}{l}\text { Far West } \\
\text { NSW }\end{array}$ & WA & $\begin{array}{l}\text { North } \\
\text { QLD }\end{array}$ & Total \\
\hline No. of health centres | client records & $13 \mid 136$ & \begin{tabular}{l|l|l}
2 & 45
\end{tabular} & $6 \mid 103$ & \begin{tabular}{r|r|}
$9 \mid$ \\
193
\end{tabular} & \begin{tabular}{l|l|l}
4 & 58
\end{tabular} & $\begin{array}{l}34 \mid \\
535\end{array}$ \\
\hline \multicolumn{7}{|l|}{ First antenatal assessment } \\
\hline Blood group/Rhesus & $96 \%$ & $100 \%$ & $65 \%$ & $77 \%$ & $79 \%$ & $82 \% *$ \\
\hline Antibodies & $93 \%$ & $100 \%$ & $66 \%$ & $70 \%$ & $78 \%$ & $79 \% *$ \\
\hline MSU & $91 \%$ & $96 \%$ & $40 \%$ & $67 \%$ & $76 \%$ & $71 \% *$ \\
\hline FBE & $95 \%$ & $100 \%$ & $64 \%$ & $73 \%$ & $79 \%$ & $80 \% *$ \\
\hline Rubella & $92 \%$ & $100 \%$ & $61 \%$ & $70 \%$ & $78 \%$ & $77 \% *$ \\
\hline $\mathrm{HBsAg}$ & $91 \%$ & $100 \%$ & $56 \%$ & $75 \%$ & $79 \%$ & $78 \% *$ \\
\hline Syphilis serology & $94 \%$ & $100 \%$ & $58 \%$ & $55 \%$ & $81 \%$ & $72 \% *$ \\
\hline HIV & $80 \%$ & $89 \%$ & $14 \%$ & $72 \%$ & $59 \%$ & $63 \% *$ \\
\hline Offered fetal anomaly screening & $6 \%$ & $33 \%$ & $17 \%$ & $20 \%$ & $0 \%$ & $15 \% *$ \\
\hline \multicolumn{7}{|l|}{ Fetal anomaly screening } \\
\hline Client agreed to fetal anomaly screening & $3 \%$ & $18 \%$ & $18 \%$ & $15 \%$ & $0 \%$ & $11 \% *$ \\
\hline Nuchal translucency & $0 \%$ & $13 \%$ & $6 \%$ & $3 \%$ & $0 \%$ & $3 \% *$ \\
\hline First trimester combined screen & $0 \%$ & $11 \%$ & $10 \%$ & $3 \%$ & $2 \%$ & $4 \% *$ \\
\hline Maternal serum screening 14-20 weeks & $2 \%$ & $2 \%$ & $17 \%$ & $8 \%$ & $2 \%$ & $7 \% *$ \\
\hline \multicolumn{7}{|l|}{ Investigations between 20 and 28 weeks } \\
\hline $\begin{array}{l}50 \text { or } 70 \mathrm{~g} \text { glucose challenge test or glucose tolerance } \\
\text { test }\end{array}$ & $78 \%$ & $49 \%$ & $33 \%$ & $38 \%$ & $66 \%$ & $51 \% *$ \\
\hline FBE & $82 \%$ & $69 \%$ & $24 \%$ & $46 \%$ & $60 \%$ & $54 \% *$ \\
\hline \multicolumn{7}{|l|}{ Investigation between 34 and 37 weeks } \\
\hline Low vaginal swab for GBS & $49 \%$ & $62 \%$ & $31 \%$ & $29 \%$ & $10 \%$ & $35 \% *$ \\
\hline \multicolumn{7}{|l|}{ Routine ultrasound check } \\
\hline Before 16 weeks & $32 \%$ & $49 \%$ & $38 \%$ & $39 \%$ & $24 \%$ & $36 \%$ \\
\hline 16-20 weeks & $47 \%$ & $69 \%$ & $31 \%$ & $41 \%$ & $34 \%$ & $42 \%$ \\
\hline
\end{tabular}

$\mathrm{FBE}=$ full blood examination, GBS = group B streptococcus, HBsAg = hepatitis B antigen, HIV = human immunodeficiency virus, MSU = midstream urine. ${ }^{*} \mathrm{P}<0.05$ for comparisons between regions.

Overall, there was good documentation around routine checks in pregnancy such as blood pressure, and in the follow up of abnormal clinical findings related to hypertension and GDM, where rates of specialist examination were high. Wide variations were present in documentation of routine investigations such as morphology ultrasound and screening tests for GDM and GBS. On average documentation of these procedures was only around $40-50 \%$, despite evidence for treatment of carbohydrate intolerance in pregnancy [26] and GBS screening [27].

Across all services, prescription of peri-conceptional folic acid supplements was low. These findings may reflect later presentation for care in pregnancy and indicate that fortified food is a potentially important source of folate to protect against neural tube defects (NTD) in those communities. Importantly, Australia recently introduced a policy of mandatory fortification of certain foods with folic acid for additional protection against NTD.

Uptake of fetal anomaly screening was low, which supports previous calls for the development of culturally safe resources around these tests [13]. There is considerable room for improvement in other aspects of antenatal counselling and education. Good evidence exists for the effectiveness of smoking cessation advice in pregnancy [28], yet documentation of this information was present for only $46 \%$ of smokers, despite the high proportion of women with recorded use of cigarettes. There was virtually no change in the proportion of women who smoked in the first compared to the third trimester overall, although in two regions the proportion declined (Top End 32\%-21\%; WA 32\%-26\%) (Table 3). Cessation advice that is inappropriate to the cultural context may be a barrier to addressing smoking in pregnancy [29] and we await the results of a controlled trial of a culturally-specific smoking intervention for pregnant Indigenous women [30]. It should be noted that many mainstream maternity units in Australia do not have relevant smoking cessation protocols [31].

In the postnatal period, only $55 \%$ of women received breastfeeding advice, and there was poor documentation of advice around smoking, hygiene, injury prevention and SIDS prevention. This is a significant area for improvement given the high prevalence of SIDS risk factors such as smoking, preterm birth and low birth-weight in these 
Table 5 Response to abnormal clinical findings

\begin{tabular}{|c|c|c|c|c|c|c|}
\hline & NT Top End & $\begin{array}{l}\text { NT Central } \\
\text { Australia }\end{array}$ & $\begin{array}{l}\text { Far West } \\
\text { NSW }\end{array}$ & WA & North QLD & Total \\
\hline No. of health centres | client records & $13 \mid 136$ & $2 \mid 45$ & \begin{tabular}{l|l|l}
6 & 103
\end{tabular} & \begin{tabular}{l|l|l}
9 & 193
\end{tabular} & \begin{tabular}{l|l}
48 \\
\end{tabular} & $34 \mid 535$ \\
\hline Record of abnormal BMI $(<20$ or $>30)$ & $3 \%(4 / 136)$ & $20 \%(9 / 45)$ & $2 \%(2 / 103)$ & $6 \%(12 / 193)$ & $5 \%(3 / 58)$ & $6 \%(30 / 535)^{*}$ \\
\hline Documented plan of management & $0 \%(0 / 4)$ & $44 \%(4 / 9)$ & $0 \%(0 / 2)$ & $0 \%(0 / 12)$ & $0 \%(0 / 3)$ & $13 \%(4 / 30)^{*}$ \\
\hline $\begin{array}{l}\text { Record of abnormal BP }(\geq 140 / 90) \text { prior to } \\
28 \text { weeks }\end{array}$ & $1 \%(2 / 136)$ & $11 \%(5 / 45)$ & $1 \%(1 / 103)$ & $0 \%(0 / 193)$ & $0 \%(0 / 58)$ & $2 \%(8 / 535)^{*}$ \\
\hline Follow up BP done & $100 \%(2 / 2)$ & $60 \%(3 / 5)$ & $100 \%(1 / 1)$ & $\mathrm{n} / \mathrm{a}$ & $\mathrm{n} / \mathrm{a}$ & $75 \%(6 / 8)$ \\
\hline Urine tested for protein & $100 \%(2 / 2)$ & $60 \%(3 / 5)$ & $100 \%(1 / 1)$ & $\mathrm{n} / \mathrm{a}$ & $\mathrm{n} / \mathrm{a}$ & $75 \%(6 / 8)$ \\
\hline GP/Obstetric referral & $50 \%(1 / 2)$ & $80 \%(4 / 5)$ & $100 \%(1 / 1)$ & $\mathrm{n} / \mathrm{a}$ & $\mathrm{n} / \mathrm{a}$ & $75 \%(6 / 8)$ \\
\hline Examination by GP/Obstetrician & $50 \%(1 / 2)$ & $80 \%(4 / 5)$ & $100 \%(1 / 1)$ & $\mathrm{n} / \mathrm{a}$ & $\mathrm{n} / \mathrm{a}$ & $75 \%(6 / 8)$ \\
\hline Anti-hypertensive medication prescribed & $50 \%(1 / 2)$ & $20 \%(1 / 5)$ & $100 \%(1 / 1)$ & $\mathrm{n} / \mathrm{a}$ & $\mathrm{n} / \mathrm{a}$ & $38 \%(3 / 8)$ \\
\hline $\begin{array}{l}\text { Record of abnormal BP }(\geq 140 / 90) \text { at or } \\
\text { after } 28 \text { weeks }\end{array}$ & $1 \%(1 / 136)$ & $13 \%(6 / 45)$ & $5 \%(5 / 103)$ & $3 \%(6 / 193)$ & $0 \%(0 / 58)$ & $3 \%(18 / 535)^{*}$ \\
\hline Follow up BP done & $100 \%(1 / 1)$ & $100 \%(6 / 6)$ & $60 \%(3 / 5)$ & $50 \%(3 / 6)$ & $\mathrm{n} / \mathrm{a}$ & $72 \%(13 / 18)$ \\
\hline Urine tested for protein & $100 \%(1 / 1)$ & $100 \%(6 / 6)$ & $60 \%(3 / 5)$ & $50 \%(3 / 6)$ & $\mathrm{n} / \mathrm{a}$ & $72 \%(13 / 18)$ \\
\hline GP/Obstetric referral & $100 \%(1 / 1)$ & $100 \%(6 / 6)$ & $60 \%(3 / 5)$ & $50 \%(3 / 6)$ & $\mathrm{n} / \mathrm{a}$ & $72 \%(13 / 18)$ \\
\hline Examination by GP/Obstetrician & $100 \%(1 / 1)$ & $100 \%(6 / 6)$ & $100 \%(5 / 5)$ & $50 \%(3 / 6)$ & $\mathrm{n} / \mathrm{a}$ & $83 \%(15 / 18)$ \\
\hline Anti-hypertensive medication prescribed & $100 \%(1 / 1)$ & $33 \%(2 / 6)$ & $0 \%(0 / 5)$ & $17 \%(1 / 6)$ & $\mathrm{n} / \mathrm{a}$ & $22 \%(4 / 18)$ \\
\hline $\begin{array}{l}\text { Record of abnormal standard glucose } \\
\text { challenge test }\end{array}$ & $17 \%(23 / 136)$ & $22 \%(10 / 45)$ & $10 \%(10 / 103)$ & $4 \%(7 / 193)$ & $17 \%(10 / 58)$ & $11 \%(60 / 535)^{*}$ \\
\hline GTT undertaken & $87 \%(20 / 23)$ & $90 \%(9 / 10)$ & $80 \%(8 / 10)$ & $43 \%(3 / 7)$ & $60 \%(6 / 10)$ & $77 \%(46 / 60)$ \\
\hline Rhesus negative & $1 \%(1 / 136)$ & $0 \%(0 / 45)$ & $7 \%(7 / 103)$ & $4 \%(8 / 193)$ & $3 \%(2 / 58)$ & $3 \%(18 / 535)^{*}$ \\
\hline Anti-D injection given $26-28$ wks & $100 \%(1 / 1)$ & $\mathrm{n} / \mathrm{a}$ & $43 \%(3 / 7)$ & $63 \%(5 / 8)$ & $0 \%(0 / 2)$ & $50 \%(9 / 18)$ \\
\hline Anti-D injection given $34-36$ wks & $100 \%(1 / 1)$ & $\mathrm{n} / \mathrm{a}$ & $29 \%(2 / 7)$ & $63 \%(5 / 8)$ & $0 \%(0 / 2)$ & $40 \%(8 / 18)$ \\
\hline Baby Rhesus positive & $0 \%(0 / 136)$ & $33 \%(15 / 45)$ & $2 \%(2 / 103)$ & $1 \%(2 / 193)$ & $0 \%(0 / 58)$ & $4 \%(19 / 535)^{*}$ \\
\hline Mother given anti-D postnatal & $\mathrm{n} / \mathrm{a}$ & $0 \%(0 / 15)$ & $100 \%(2 / 2)$ & $100 \%(2 / 2)$ & $\mathrm{n} / \mathrm{a}$ & $21 \%(4 / 19)^{*}$ \\
\hline Anaemia $(\mathrm{Hb}<100 \mathrm{~g} / \mathrm{L})$ & $14 \%(19 / 136)$ & $22 \%(10 / 45)$ & $11 \%(11 / 103)$ & $12 \%(24 / 193)$ & $3 \%(2 / 58)$ & $12 \%(66 / 535)^{*}$ \\
\hline Iron prescribed & $84 \%(16 / 19)$ & $100 \%(10 / 10)$ & $91 \%(10 / 11)$ & $75 \%(18 / 24)$ & $50 \%(1 / 2)$ & $83 \%(55 / 66)$ \\
\hline Follow up FBE or $\mathrm{Hb}$ test done & $42 \%(8 / 19)$ & $90 \%(9 / 10)$ & $36 \%(4 / 11)$ & $46 \%(11 / 24)$ & $50 \%(1 / 2)$ & $50 \%(33 / 66)$ \\
\hline Nitrites detected by dip stick & $21 \%(28 / 136)$ & $33 \%(15 / 45)$ & $5 \%(5 / 103)$ & $24 \%(46 / 193)$ & $10 \%(6 / 58)$ & $19 \%(100 / 535)^{*}$ \\
\hline Urine sent for MSU & $96 \%(27 / 28)$ & $100 \%(15 / 15)$ & $100 \%(5 / 5)$ & $93 \%(43 / 46)$ & $100 \%(6 / 6)$ & $96 \%(96 / 100)$ \\
\hline Oral antibiotic prescribed & $93 \%(26 / 28)$ & $60 \%(9 / 15)$ & $80 \%(4 / 5)$ & $37 \%(17 / 46)$ & $83 \%(5 / 6)$ & $61 \%(61 / 100)^{*}$ \\
\hline Record of a normal follow up MSU & $46 \%(13 / 28)$ & $100 \%(15 / 15)$ & $40 \%(2 / 5)$ & $26 \%(12 / 46)$ & $83 \%(5 / 6)$ & $47 \%(47 / 100)^{*}$ \\
\hline Rubella antibodies negative or low titre & $35 \%(47 / 136)$ & $7 \%(3 / 45)$ & $15 \%(15 / 103)$ & $15 \%(28 / 193)$ & $7 \%(4 / 58)$ & $18 \%(97 / 535)^{*}$ \\
\hline Rubella immunisation given postnatally & $36 \%(17 / 47)$ & $67 \%(2 / 3)$ & $13 \%(2 / 15)$ & $32 \%(9 / 28)$ & $0 \%(0 / 4)$ & $31 \%(30 / 97)$ \\
\hline
\end{tabular}

$\mathrm{BP}=$ blood pressure, $\mathrm{BMI}=$ body mass index, $\mathrm{FBE}=$ full blood examination, $\mathrm{GP}=$ general practitioner, $\mathrm{GTT}=$ glucose tolerance test, $\mathrm{Hb}=$ haemoglobin, $\mathrm{MSU}=$ midstream urine, $\mathrm{n} / \mathrm{a}=$ not applicable.

${ }^{*} P<0.05$ for comparisons between regions.

communities. Overall, this indicates there is great potential to improve the continuity of care throughout the antenatal and postnatal period. It should be noted that centres in this study do not provide birthing services; local policies currently require women in remote areas to be transferred into regional hospitals for birthing from 36 weeks gestation. Therefore, attempts to improve continuity in this setting will require better integration of services or a redesign of care to support communitybased services across the spectrum of maternity care. This was acknowledged in the recent report of the Australian Maternity Services Review [32], which also recognised the importance of provision of services to
Indigenous women that accommodate cultural beliefs about childbirth, including in some communities, a preference for 'birthing on country'.

The findings of this study are subject to some limitations. Participating services have a history of involvement in quality improvement activities, expanded from a focus on chronic disease management to maternal, child and other aspects of health, which may limit the generalisability of findings. The maternal audit was undertaken to provide baseline data for individual services with an interest in improving delivery of maternal health care, as part of an on-going quality improvement study (the $\mathrm{ABCD}$ project). Not all services participating in this larger study elected to 
Table 6 Recording of brief interventions after birth

\begin{tabular}{|c|c|c|c|c|c|c|}
\hline & NT Top End & NT Central Australia & Far West NSW & WA & North QLD & Total \\
\hline No. of health centres | client records & $13 \mid 136$ & $2 \mid 45$ & \begin{tabular}{l|l|l}
6 & 103
\end{tabular} & $9 \mid 193$ & $4 \mid 58$ & $34 \mid 535$ \\
\hline Recorded postnatal visit & $55 \%$ & $87 \%$ & $65 \%$ & $41 \%$ & $36 \%$ & $53 \%^{*}$ \\
\hline \multicolumn{7}{|l|}{ Brief interventions/counselling } \\
\hline Smoking & $12 \%$ & $27 \%$ & $25 \%$ & $17 \%$ & $24 \%$ & $19 \%$ \\
\hline Nutrition & $13 \%$ & $42 \%$ & $26 \%$ & $15 \%$ & $34 \%$ & $21 \% *$ \\
\hline Breast feeding & $37 \%$ & $82 \%$ & $65 \%$ & $42 \%$ & $31 \%$ & $47 \% *$ \\
\hline Infection prevention/hygiene & $7 \%$ & $7 \%$ & $3 \%$ & $5 \%$ & $5 \%$ & $5 \%$ \\
\hline Injury prevention & $1 \%$ & $0 \%$ & $9 \%$ & $4 \%$ & $2 \%$ & $4 \%$ \\
\hline SIDS prevention & $1 \%$ & $2 \%$ & $17 \%$ & $4 \%$ & $0 \%$ & $5 \% *$ \\
\hline Alcohol and other substance abuse & $5 \%$ & $9 \%$ & $21 \%$ & $15 \%$ & $16 \%$ & $13 \% *$ \\
\hline Physical activity & $5 \%$ & $20 \%$ & $21 \%$ & $9 \%$ & $19 \%$ & $12 \%^{*}$ \\
\hline Mood (depression) & $13 \%$ & $33 \%$ & $31 \%$ & $19 \%$ & $7 \%$ & $20 \% *$ \\
\hline Contraception & $41 \%$ & $82 \%$ & $56 \%$ & $34 \%$ & $24 \%$ & $43 \% *$ \\
\hline Domestic/social environment & $8 \%$ & $22 \%$ & $7 \%$ & $11 \%$ & $10 \%$ & $10 \% *$ \\
\hline Social/family support & $12 \%$ & $44 \%$ & $20 \%$ & $19 \%$ & $9 \%$ & $19 \% *$ \\
\hline Financial situation & $3 \%$ & $7 \%$ & $3 \%$ & $9 \%$ & $2 \%$ & $5 \%$ \\
\hline Housing condition & $1 \%$ & $20 \%$ & $1 \%$ & $15 \%$ & $3 \%$ & $8 \% \%^{*}$ \\
\hline Food security & $1 \%$ & $16 \%$ & $0 \%$ & $6 \%$ & $2 \%$ & $4 \% *$ \\
\hline
\end{tabular}

SIDS = sudden infant death syndrome.

${ }^{*} \mathrm{P}<0.05$ for comparisons between regions.

audit maternal records, which may also limit the generalisability of findings. Our audit data provide similar estimates of mean maternal age and smoking prevalence, but lower estimates of preterm birth and low birth weight than estimates reported in routine NT, WA, QLD and NSW Indigenous perinatal information [2]. As such, our data should not be regarded as representative of all services in the regions. Furthermore, small numbers of abnormal findings in this sample means estimates of rates of follow up of abnormal findings lack precision. The data presented here are baseline service activity only; more data will be available for subsequent years of the quality improvement intervention, which includes annual cycles of organisational assessment, clinical audits, feedback to and interpretation of data with participating health centre staff, action planning, goal setting and implementing of strategies for change [18].

The measures of quality of care reported in this study provide important data for feedback to services at a local level. When aggregated, they provide a picture of regional patterns of maternity care which will be progressively more informative for broad scale policy and program purposes as increasing numbers of services become involved. Importantly, these measures provide information that is not currently available from routinely collected perinatal data [2].

There is increasing activity in Australia and internationally around assessment of maternity care, with the completion several projects designed to facilitate benchmarking of services [33-35]. The two recent Australian projects recommended a core set of indicators focussing on intrapartum and postpartum clinical outcomes. In developing our study we had difficulty choosing measures of quality of maternal health care relevant for the community health centre setting. Reporting on the proposed national maternity indicators would require information from other systems such as hospital administrative data. It is also unrealistic to expect to show improvements in outcomes such as low birth weight over annual cycles of quality improvement activities. We chose to focus on processes of antenatal and postnatal care, which reflect delivery of routine screening investigations and treatment of abnormal findings, consistent with local guidelines for the community health setting. We recognise that like the proposed national indicators, this presents an incomplete picture of the scope of maternity care. A coordinated and consistent national approach to reporting of maternity information across all services (primary, secondary and tertiary) is needed, building on the substantial work of the National Perinatal Statistics Unit within the Australian Institute of Health and Welfare in national perinatal data development. Achieving this will require consensus on standard components of antenatal care, and so it is critical for Governments to continue to support the development of national guidelines defining best practice in antenatal care in Australia, such as those in the United Kingdom [36].

\section{Conclusion}

Supporting services to improve maternity care for Indigenous women is a recognised priority [16] given the 
persistence of unacceptably high rates of poor Indigenous perinatal outcomes. This is acknowledged by Indigenous women, who consistently identify optimising the health of mothers and babies as a high priority $[21,37,38]$. This study demonstrates that although Indigenous women presented at a later gestational age they regularly attended services for maternity care, with the average total number of antenatal visits within suggested minimum numbers $[5,20]$. Importantly, this indicates that there are opportunities for appropriate investigation and risk factor intervention amongst Indigenous women. The findings highlight the inadequacy of existing systems in community health centres to provide access to routine evidence-based screening and health information in the antenatal and postnatal period. More broadly, the findings reflect the lack of consistency in national standards defining antenatal care that all Australian women should expect to receive, which unless addressed, will see the persistence of inequalities in maternity care and outcomes.

\section{List of abbreviations used}

ABCD: Audit and Best practice for Chronic Disease; BMI: Body Mass Index; BP: Blood Pressure; FBE: Full Blood Examination; FHR: Fetal Heart Rate; GBS: Group B Streptococcus; GDM: Gestational diabetes mellitus; GP: General Practitioner; GTT: Glucose Tolerance Test; Hb: Haemoglobin; HBsAg: Hepatitis B Antigen; HIV: Human Immunodeficiency Virus; MSU: Midstream Urine; NSW: New South Wales; NT: Northern Territory; NTD: Neural Tube Defects; QLD: Queensland; Rh: Rhesus; SIDS: Sudden Infant Death Syndrome; WA: Western Australia; WBM: Women's Business Manual.

\section{Acknowledgements}

This project would not be possible without the active support, enthusiasm and commitment of staff and management of the participating health services and the contribution made by the wider $A B C D$ project team. The $A B C D$ project is supported by funding from the Cooperative Research Centre for Aboriginal Health and the Commission for Safety and Quality in Health Care. The work of a number of people with key roles in the project is supported by their employing organisations, including State and Territory governments and community controlled health organisations. RSB's work is supported by NHMRC Fellowship \#283303, ARR's work is supported by a NHMRC Population Health Capacity Building Grant (\#236235), and the Jean B Reid Fellowship from the University of Adelaide Medical Endowment Fund.

\section{Author details}

'Discipline of Obstetrics and Gynaecology, The University of Adelaide, Adelaide, SA, Australia. ${ }^{2}$ Menzies School of Health Research, Darwin, NT, Australia. ${ }^{3}$ Centre for Chronic Disease, The University of Queensland, Brisbane, QLD, Australia. ${ }^{4}$ Ngalkanbuy Health Service, Elcho Island, NT, Australia. ${ }^{5}$ Marri Ma Health Aboriginal Corporation, Broken Hill, NSW, Australia. ${ }^{6}$ Combined Universities Centre for Rural Health, University of Western Australia. ${ }^{7}$ Menzies School of Health Research, Alice Springs, NT, Australia. ${ }^{8}$ Queensland Health, Brisbane, QLD, Australia. ${ }^{9}$ Centre for Indigenous Vascular and Diabetes Research, Baker IDI Heart and Diabetes Institute, Alice Springs, NT, Australia. ${ }^{10}$ Public Health Division, Department of Health, Government of Western Australia, Perth, WA, Australia. ${ }^{11}$ Northern Territory Department of Health and Families, Darwin, NT, Australia.

\section{Authors' contributions}

ARR played a primary role in the interpretation of study results and preparation of the manuscript. RSB developed the study design, managed the implementation of the study, and played a primary role in the interpretation of study results and preparation of the manuscript. DS was responsible for data management and data analysis and contributed to preparation of the manuscript. MCD, RJC, LO, HEL, RKK, SCT, HPB, ADHB, TW,
CMC provided expert advice in contextualising study findings, particularly in relation to each jurisdiction, and assisted with preparation and editing of the manuscript. All authors read and approved the final manuscript.

\section{Competing interests}

The authors declare that they have no competing interests.

Received: 7 October 2010 Accepted: 7 March 2011

Published: 7 March 2011

\section{References}

1. Australian Bureau of Statistics (ABS) and Australian Institute of Health and Welfare (AlHW): The Health and Welfare of Australia's Aboriginal and Torres Strait Islander Peoples. Canberra: ABS \& AIHW; 2008, ABS Catalogue No. 4704.0.

2. AlHW: Leeds KL, et al: Indigenous mothers and their babies, Australia 2001-2004. Canberra: AlHW; 2008.

3. AlHW: Aboriginal and Torres Strait Islander Health Performance Framework: 2008 report: Detailed analyses. Canberra: AlHW; 2008, Catalogue. no. IHW 22

4. Barker DJP: Mothers, babies, and disease in later life. London: BMJ Publishing Group; 1994.

5. Carroli G, Villar J, Piaggio G, Khan-Neelofur D, Gulmezoglu M, Mugford M, Lumbiganon P, Farnot U, Bersgio P, WHO Antenatal Care Trial Research Group: WHO systematic review of randomised controlled trials of routine antenatal care. Lancet 2001, 357:1565-70.

6. de Costa C, Child A: Pregnancy outcomes in urban aboriginal women. MJA 1996, 164(9):523-526.

7. Mackerras D: Evaluation of the Strong Women, Strong Babies, Strong Culture Program: Results for the period 1990-1996 in the three pilot communities. Darwin: Menzies School of Health Research Occasional Papers; 1998.

8. Powell J, Dugdale AE: Obstetric outcomes in an Aboriginal community: A comparison with the surrouding rural area. Aust J Rural Health 1999, 7:13-17.

9. National Indigenous Health Equality Council: Child mortality target: analysis and recommendations. 2010 [http://www.nihec.gov.au/internet/ nihec/publishing.nsf/Content/Child-Mortality-Analysis], Accessed 29th April 2010.

10. United Nations: The Milennium Development Goals Report 2010. New York: United Nations Department of Economic and Social Affairs (DESA); 2010.

11. Mensch B: Quality of care: a neglected dimension. In The health of women: a global perspective. Edited by: Koblinsky M, Timyan J, Gay J. Colorado: West View Press; 1993:235-253.

12. Mathole T, Lindmark G, Majoko F, Ahlberg BM: A qualitative study of women's perspectives of antenatal care in a rural area of Zimbabwe. Midwifery 2004, 20(2):122-132.

13. Hunt J: Trying to make a difference improving pregnancy outcomes, care and services for Australian Indigenous women. PhD thesis. La Trobe University, Bundoora, Victoria, Australia; 2003.

14. Panaretto KS, Lee HM, Mitchell MR, Larkins SL, Manessis V, Buettner PG, Watson D: Impact of a collaborative shared antenatal care program for urban Indigenous women: a prospective cohort study. MJA 2005, 182(10):514-519.

15. Panaretto KS, Mitchell MR, Anderson L, Larkins SL, Manessis V, Buettner PG, Watson D: Sustainable antenatal care services in an urban Indigenous community: the Townsville experience. MJA 2007, 187(1):18-22.

16. Australian Government Department of Health Ageing: Healthy for Life Program Framework. 2008 [http://www.health.gov.au/internet/h4l/ publishing.nsf/Content/framework], Accessed 1st September 2008.

17. Bailie RS, Si D, O'Donoghue L, Dowden M: Indigenous health: effective and sustainable health services through continuous quality improvement. MJA 2007, 186:525-527.

18. Bailie RS, Togni SJ, Si D, Robinson G, d'Abbs PH: Preventive medical care in remote Aboriginal communities in the Northern Territory: a follow-up study of the impact of clinical guidelines, computerised recall and reminder systems, and audit and feedback. BMC Health Serv Res 2003, 3(1):15.

19. Three Centres Guidelines: Three Centres Consensus Guidelines on Antenatal Care Project, Mercy Hospital for Women, Southern Health and 
Women and Children's Health 2001. [http://www.health.vic.gov.au/ maternitycare/pubs.htm], Accessed 20th September 2008.

20. Congress Alukura and Nganampa Health Council Incorporated: Minymaku Kutju Tjukurpa Women's Business Manual. Alice Springs: Congress Alukura and Nganampa Health Council Inc; 2008.

21. Eades S: Maternal and child health care services: Actions in the primary health care setting to improve the health of Aboriginal and Torres Strait Islander women of childbearing age, infants and young children. Aboriginal and Torres Strait Islander Primary Health Care Review: Consultation Report Number 6 Darwin: Menzies School of Health Research; 2004.

22. Herceg A: Improving health in Aboriginal and Torres Strait Islander mothers, babies and young children: a literature review. Canberra: Office of Aboriginal and Torres Strait Islander Health, Australian Government Department of Health and Ageing; 2005.

23. National Aboriginal and Torres Strait Islander Nutrition Working Party for the Strategic Intergovernmental Nutrition Alliance, National Public Health Partnership (NPHP): National Aboriginal and Torres Strait Islander nutrition strategy and action plan 2000-2010. Canberra: NHPH; 2000.

24. National Aboriginal and Torres Strait Islander Child and Maternal Health Exemplar Site Initiative: Site Reports 2005. Canberra: Office of Aboriginal and Torres Strait Islander Health; 2005.

25. Rumbold AR, Bailie RS, Si D, Dowden MC, Kennedy CM, Cox RJ, O'Donoghue L, Liddle HE, Kwedza RK, Thompson SC, Burke HP, Brown AD, Weeramanthri T, Connors CM: Assessing the quality of maternal health care in Indigenous primary care services. MJA 2010, 192(10):597-8.

26. Crowther CA, Hiller JE, Moss JR, McPhee AJ, Jeffries WS, Robinson JS: Effect of treatment of gestational diabetes mellitus on pregnancy outcomes. $N$ Engl J Med 2005, 352(24):2477-2486.

27. Schrag SJ, Zell ER, Lynfield R, Roome A, Arnold KE, Craig AS, Harrison LH, Reingold A, Stefonek K, Smith G, Gamble M, Schuchat A: A populationbased comparison of strategies to prevent early-onset group $B$ streptococcal disease in neonates. N Engl J Med 2002, 347(4):233-239.

28. Lumley J, Oliver SS, Chamberlain C, Oakley L: Interventions for promoting smoking cessation during pregnancy. The Cochrane Database of Systematic Reviews 2004, , 4: CD001055.

29. Wood L, France K, Hunt K, Eades S, Slack-Smith L: Indigenous women and smoking during pregnancy: Knowledge, cultural contexts and barriers to cessation. Social Science \& Medicine 2008, 66(11):2378-2389

30. Panaretto KS, Mitchell MR, Anderson L, Gilligan C, Buettner P, Larkins SL, Eades $\mathrm{S}$ : Tobacco use and measuring nicotine dependence among urban Indigenous pregnant women. MJA 2009, 191(10):554-7.

31. Hunt J, Lumley J: Are recommendations about routine antenatal care in Australia consistent and evidence-based? MJA 2002, 176:255-9.

32. Australian Government Department of Health and Ageing: Improving Maternity Services in Australia: The Report of the Maternity Services Review. Canberra: Commonwealth of Australia; 2009 [http://www.health. gov.au/internet/main/publishing.nsf/Content/maternityservicesreviewreport], Accessed 8th February 2011.

33. Women's Hospitals Australasia: Supporting excellence in maternity care: The Core Maternity Indicators Project. 2007 [http://www.wcha.asn.au/ index.cfm/spid/1_49.cfm], Accessed 21st September 2008.

34. Australian Council on Health Care Standards (ACHS): ACHS Obstetric Clinical Indicator Users' Manual 2010. Ultimo, NSW: ACHS Performance and Outcomes Service; 2010

35. Healthcare Comission: Towards better births: A review of maternity services in England. London: (c) Commission for Health Care Audit and Inspection; 2008

36. National Institute for Health and Clinical Excellence (NICE): Antenatal care: routine care for the healthy pregnant woman. In NICE clinical guideline 62 . London: NICE; 2008.

37. Carter E, Lumley J, Wilson G: 'Alukura... for my daughters and their daughters and their daughters'. A review of Congress Alukura. Australian and New Zealand Journal of Public Health 2004, 28:229-34.

38. Stamp GE, Champion S, Anderson G, Warren B, Stuart-Butler D, Doolan J, Boles C, Callaghan L, Foale A, Muyambi C: Aboriginal maternal and infant care workers: partners in caring for Aboriginal mothers and babies. Rural and Remote Health 2008, 8:883.

\section{Pre-publication history}

The pre-publication history for this paper can be accessed here:

http://www.biomedcentral.com/1471-2393/11/16/prepub doi:10.1186/1471-2393-11-16

Cite this article as: Rumbold et al: Delivery of maternal health care in Indigenous primary care services: baseline data for an ongoing quality improvement initiative. BMC Pregnancy and Childbirth 2011 11:16.

\section{Submit your next manuscript to BioMed Central and take full advantage of:}

- Convenient online submission

- Thorough peer review

- No space constraints or color figure charges

- Immediate publication on acceptance

- Inclusion in PubMed, CAS, Scopus and Google Scholar

- Research which is freely available for redistribution

Submit your manuscript at www.biomedcentral.com/submit
Ciomed Central 